\title{
A point of connection? Well-being, the veteran identity and older adults
}

\section{Title page}

Title: A point of connection? Well-being, the veteran identity and older adults

Authors: Liz Brewster, ${ }^{1}$ Brigit McWade, ${ }^{1}$ Samuel J.A. Clark ${ }^{2}$

${ }^{1}$ Lancaster Medical School, Lancaster University, Lancaster, UK

${ }^{2}$ Department of Politics, Philosophy, and Religion, Lancaster University, Lancaster, UK

Corresponding author: Liz Brewster, Lancaster Medical School, Faculty of Health \& Medicine, Furness College, Lancaster University, Lancaster, LA1 4YG.

Email: e.brewster@lancaster.ac.uk

\section{Author ORCIDs}

Liz Brewster 0000-0003-3604-2897

Brigit McWade 0000-0003-4351-7299

Samuel J.A. Clark 0000-0002-8392-1651

\section{Statement of funding}

This work was supported as part of the Royal British Legion Healthy Living Portfolio by the Aged Veterans Fund funded by the Chancellor using LIBOR funds. The funder played no role in the design, execution, analysis and interpretation of the data, or writing of the study.

\section{Declaration of contribution of authors}

All authors contributed to the conception, design, analysis and interpretation of data. LB drafted the article and BM and SC revised it. All authors approve the version to be published.

\section{Statement of conflict of interest}

The authors declare no conflicts of interest.

\section{Acknowledgements}

The authors would like to thank all participants for their contributions.

\section{Statement of ethical approval}

Ethical approval for this study was granted by the Lancaster University Faculty of Health and Medicine Research Ethics Committee (ref: FHMREC16125) 


\section{Abstract}

Maintaining good well-being in older age is seen to have a positive effect on health, including cognitive and physiological functioning. This paper explores experiences of well-being in a particular older adult community: those who have served in the military. It aims to identify the specific challenges that ex-service personnel may have, reporting findings from a qualitative study focused on how older veterans told stories of military service and what these stories revealed about well-being.

We used a qualitative approach; data are drawn from 30 individual interviews, and from engagement with veterans in workshops. Analysis was conducted using a data-driven constant comparison approach. Three themes are presented: how loneliness affects older adult veterans; how they draw on fictive kinship; the role of military visual culture.

Although participants had diverse experiences of military service, they felt that being a veteran connected them to a community that went beyond association with specific experiences. Using narratives of military experience to connect, both in telling stories and by stories being listened to, was vital. As veterans, older adults were able to access each other as a resource for listening and sharing. However, it was also exclusionary: civilians, because they lacked military service experience, could not empathise and be used as a resource.

\section{Keywords}

Well-being, military veterans, social support 


\section{A point of connection? Well-being, the veteran identity and older adults}

\section{Introduction}

Concerns about maintaining good well-being in older age have been widely reported (Steptoe, Deaton and Stone, 2015). Well-being is a widely debated and complex concept; there is little agreement about what it 'is', particularly from a philosophical standpoint (Schechtman, 1996; Dodge et al., 2012). There are many models which attempt to define what affect well-being in daily life, often focusing on individual characteristics including engagement, meaning and accomplishments (Nussbaum, 2005; Dolan, Peasgood and White, 2008; Seligman, 2011). Our broad definition of well-being takes into account the relational nature of well-being, which 'emerges collectively, rooted in different domains in life as well as through our biographies' (Cieslik, 2017, pp. 67-68). Well-being is therefore social, rooted in relationships and interactions, as well as individual, and so is affected both by a person's understanding of their life in their social context, and their access to social contact and perceived support.

Interest has focused on the link between well-being, social isolation and the continuation of relationships in older age. Being socially isolated is seen as a cause of decreasing levels of well-being. Older age is associated with both increased social isolation and loneliness (Victor and Yang, 2012), with higher numbers of older adults living alone (Office for National Statistics, 2015), reporting dissatisfaction with personal relationships (Cornwell and Waite, 2009; Aartsen and Jylhä, 2011) and feeling disconnected from wider society (Davisdon and Rossall, 2015). Previous research has shown that some older adults regard loneliness as an 'inevitable' part of the ageing process (Pettigrew and Roberts, 2008). As life changes including retirement and bereavement affect the social contacts available to older adults, increased loneliness has come to be regarded as a major health risk, associated with higher rates of depression and other feelings of psychological distress (Taylor et al., 
2018), Alzheimer's Disease (Wilson et al., 2007), increased blood pressure and cardiovascular disease (Steptoe et al., 2004). Loneliness is often characterised as a 'mismatch' between what support is needed and what is available (Perlman and Peplau, 1984). However, investigations of loneliness acknowledge that taking a deficit-focused approach does not allow for an exploration of what helps to maintain social networks and connectedness (Wilson, Hill and Kiernan, 2018). This paper takes a proactive focus rather than a deficit-focused one, to explore experiences of well-being in a particular older adult community: those who have, at some point in their life, served in the armed forces (exservice personnel).

Ex-service personnel were chosen as a community of interest because they represent a substantial proportion of the older adult population. At time of last estimate, ex-service personnel equated to around 1 in 8 older adults (aged over 65) in the United Kingdom (UK) population (Ministry of Defence, 2015; Randall, 2017). The current generation of UK older adults are in a distinct position in society, with a higher proportion having served in the military than in subsequent generations. This figure is a product of the introduction of National Service, which formed the basis of conscription 1939-1945, and then was enacted as a minimum two years of service from 1948-1960, with conscripts serving until 1963. However, comparison of the most recent overview surveys of the whole veteran community show a significant decline in the number of veterans: there were over 99,000 fewer veterans in 2017 than there were in 2016 (Ministry of Defence, 2019). It is presumed that this is because of deaths of older veterans, rather than significant changes in the number of current military personnel. This paper captures some of the impacts of this rapid decline on remaining older veterans.

More widely, significant concerns about veteran mental health, and by extension, well-being have been identified. These identified issues, including post-traumatic stress, alcoholism and repeated interaction with the criminal justice system are seen to affect younger communities of veterans, particularly those who have recently left the forces (Lee et al., 2002; MacManus et al., 2013). The 
data presented in this paper move away from a conceptualisation of the veteran as a 'social problem' to explore how life following military service changes the experience of older adults who have served.

\section{Identifying and defining veterans}

The term veteran is broadly used internationally to refer to people who have left military service; from the perspective of those who have served, and those who provide services and support to veterans, the definition is politically important is it is used as an inclusionary and exclusionary device to understand who is entitled to particular benefits and services. It can be caveated based on length of service, whether someone has seen 'active service' (i.e. been deployed to a combat situation) or type of discharge (e.g. honourable or dishonourable). In the USA, a veteran is defined as 'a person who served in the active military, naval, or air service and who was discharged or released under conditions other than dishonourable' (Veterans Organisation, 2019). In other countries, including Germany and the UK, a more inclusive definition of a veteran has been adopted which includes all former service personnel: anyone who has been part of the armed forces for at least one day of service is considered to be a veteran (Hansard, 2001; HM Government, 2018). Although around 1.7 million older adults are ex-service personnel, not all identify as a veteran. This inclusive definition, in use since the early 2000s, is seen to be in conflict with public perceptions of who is a veteran, and with perceptions of many ex-service personnel themselves (Burdett et al., 2013). The UK definition emerged from a need to allocate resources appropriately and ensure that ex-service personnel had access to services and benefits (Hansard, 2001; Dandeker et al., 2006). Building on this, identifying as a veteran provides access to self-organised (e.g. formed around a particular regiment) and third sector veterans organisations (e.g. the Royal British Legion). The number of veterans directly involved in veterans' organisations is difficult to estimate, but one of the largest organisations supporting veterans (of all ages) is the Royal British Legion, with around 350,000 members. This figure shows that not all ex-service personnel who could identify as a veteran or engage with veterans' organisations choose to do so. 
Identity, as a concept, is defined here as both a self-perception (how an individual sees themselves within the world) and an outward presentation (how an individual defines themselves in relation to others) (Taylor, 1992; Schechtman, 1996; Burkitt, 1999). Belonging to a veterans' organisation can be seen as an outward manifestation of adopting this identity but, as will be explored here, it was not the only way in which the veteran identity could be enacted.

The UK government's decision to adopt an inclusive definition does not match public perceptions, with one UK public survey (conducted in 2002 with 2,013 respondents) showing that that the majority (57\%) of those questioned perceived only WWI or WWII personnel as veterans (Dandeker et al., 2006). The survey indicated that $37 \%$ of those questioned did accept a broader definition of 'all exservice personnel,' though this is still not one as broad as that used to allocate resources (Dandeker et al., 2006). Similarly, another survey of 202 UK ex-service personnel (of all ages) found that they also thought of veterans as older or WWI/ WWII (Burdett et al., 2013). Only half of those ex-service personnel surveyed by Burdett et al (2013) saw themselves as a veteran when asked directly. Though all ex-service personnel surveyed did meet the definition in use in the UK, they did not think of themselves as veterans. Age, length of service, or having seen combat did not affect how likely it was for ex-service personnel to see themselves as a veteran. (Burdett et al., 2013).

This disconnect between public, ex-service personnel and government perceptions of a veteran shows that there is not a coherent and agreed veteran identity; instead, there are multiple ways that the veteran identity is understood and may be adopted. Much of the current literature on military veteran identity focuses on sociodemographic variables that impact on help-seeking and epidemiological mapping of health and social issues (Lee et al., 2002; MacManus et al., 2013, 2015). This is driven, in part, by concerns about providing adequate access to services that support military veterans, with a recognition that challenges in post-military life have a significant impact on health 
and well-being. Our contribution goes beyond these immediate issues of defining who qualifies as a veteran, though it acknowledges that there are benefits to be gained by being seen as a veteran. Some of these benefits are financial, such as access to war pensions, or practical, including specialist care services. Other effects, as will be explored in this paper, are less tangible or even negative.

Although identities are intersectional, and veterans do not exist solely as veterans, what is of interest here is how those who adopt this identity use and apply it in their post-military lives, particularly as they age. The willingness, or otherwise, to value a veteran identity is underpinned by acceptance of two fundamental beliefs. First, the idea that only by undergoing military experience can you understand being a veteran. This belief excludes those who have not undergone military experience from the veteran community. Perceptions of experiences of military service as somehow unique or transformative (one cannot understand military service unless one has undertaken military service, and one is fundamentally changed by military service) (Paul, 2014) have led to an insider/outsider divide. Those who have undertaken military service tell a story about their experience that they feel cannot be understood by those who have not had a similar experience. Veterans see the connection generated by shared experiences as one that is genuine and authentic (Burnell, Needs and Gordon, 2017).

Second, the veteran identity is mediated and constructed through narratives about veterans; what a veteran is and what they can say is limited by what it is acceptable to say about military service (Willsey, 2015). For example, veterans report learning not to tell stories of violence, trauma and anger because they alienated others (Willsey, 2015). Stories are a mediated and constructed version of events which perform a function. McAdams (1993) takes the view that such life stories construct an identity over time. There has been little previous exploration of how older adults with military experience manage this tension between using stories to construct identity and learning not to tell certain stories. 
For older veterans, the idea that their service was valued or valuable is based on dominant cultural narratives of post-war state rebuilding and national service. Reflecting on these beliefs about what it means to have been in the military demonstrates why this veteran identity is acceptable for, or accepted by, the older community. Time, memory and distance from previous events may also help to moderate any ontological fracture (Bulmer and Jackson, 2016), making it easier to hold a dominant identity as someone who is proud of military service and status as a veteran, while also separating it from traumatic experiences and critique of institutional violence.

Thus the veteran identity, separate from the technical and legal definition of a veteran used in the UK, is defined here as a 'self-concept reflecting past military identity in present civilian space'(Thompson et al., 2017). Fundamentally, the veteran identity rests on exclusion of civilians. Being a veteran rests on a perception of homogeneity; the idea that all military personnel are equal regardless of where they served, when, for how long, or whether they have seen combat. Paradoxically, the veteran identity is also seen as specific to particular situations or types of veteran (e.g. those who have seen active service) (Thompson et al., 2017). Veteran researchers, working to explore embodied experiences of being a veteran, also acknowledge this tension around perceptions of equivalence (veterans are equal) and variance (veterans are not equal) in experience (Bulmer and Jackson, 2016). We also take the position that there are diverse and different veteran stories, but also that veterans see themselves as having something indefinable in common that unites them in an unshakable bond.

\section{Fictive kinship}

Fictive kinship, the idea that someone is part of an imagined family, is widely recognised as part of a military identity. Within the concept of military-as-kin, Woodward and Jenkings (2011) posit that what makes people see their fellow service personnel as 'like family' are the strong emotional bonds associated with service, the professional expertise and skill, and the 'collectivity' of activities in 
service. Military service is seen as more than just a 'job' and this is in part why former military personnel can struggle in post-service civilian lives. Much of the literature in this area focuses on those who have undergone recent transitions from military service to civilian life, but perceptions of fictive kinship seem to be particularly relevant to older adults in general. One premise, not fully investigated, is that time and memory have an effect on maintaining fictive kinship (Woodward and Jenkings, 2011).

Older adults' recognition and use of fictive kin has highlighted that often fictive kin fill a specific need, often that of social support (Rae, 1992). Fictive kinship relationships are not always predicated on geographic location or frequent contact, but are seen as long-lasting, intimate and ones that could be relied upon (Rae, 1992). The widespread nature of veterans identifying other fellow service personnel as a form of family tells a story about group membership. Perceptions of a shared history and an 'imagined community' bond (Anderson, 2006) have been seen to have a positive impact on loneliness, even in socially-isolated groups such as older adults living in rural communities (BantryWhite et al., 2018).

The trope of 'not having to explain yet being understood' (Caddick, Phoenix and Smith, 2015) is relevant to ideas of fictive kinship and storytelling. The relational nature of stories, which are addressed to an imagined audience who understand the story, creates a dialogue which functions to reinforce fictive kinship (Frank, 2010). The perceived audience for stories also excludes those who are not recognised as part of the family, meaning that telling a story about being part of a community is also used to establish a right to holding that identity. Examining what stories are told also allows for consideration of why they are told and what effect they have (Frank, 2010).

One criticism of the use of fictive kinship as a trope to understand military veteran identity is that it relies heavily on an acceptance of dominant narratives. Within military culture, a commonly-told 
narrative is one of being broken down by basic training and rebuilt in the image of the military, with its ideals of discipline, comradeship and service. An acceptance of this narrative means that it is difficult to explain relationships between veterans in any other way; instead, the only acceptable way to talk about experiences is as an individual inculcated into the service family.

\section{Coping with post-service life as an older adult}

Alongside these broader, perhaps more philosophical discussions of what it means to be a veteran or part of the military family are more practical concerns about what happens when ex-services personnel return to civilian life. Previous research with WWII veterans has explored what coping strategies were used by those traumatised by war experiences; it identified that social support was key in managing in post-war civilian life (Hunt and Robbins, 2001a; Burnell, Coleman and Hunt, 2010). Sources of social support included previous military comrades, veterans' associations and wives and family (Hunt and Robbins, 2001b). It highlighted that as veterans aged, they seemed to call on veterans associations more as they started to experience more distress or felt that they had 'more to say' (Burnell, Coleman and Hunt, 2010). By trying to consider the role of time and distance from experience in understanding potentially traumatic events, this work highlighted the effect of ageing on an ex-service population (Hunt and Robbins, 2001a). As Phil Klay, an American veteran and author, states it took 'years to untangle' to get to a point where he felt able to give an account of his military experiences (Corley, 2017). The role of retirement as a shift in personal circumstances also plays a role here; simply having the time to think and reflect may affect perspectives on previous experience (Hunt and Robbins, 2001a).

Arthur Frank's (2010) work on stories as companions is helpful in considering and theorising how wellbeing is experienced in later life. Older adults used their military memories to form new communities with a perceived commonality or shared recognition. As a 'tacit resource' (Frank, 2010), stories of military life could be drawn on to talk with others who had also served. 
This consideration of 'uses' of stories is different from other story-telling traditions. In asking older adults to tell their stories of military life, we were not seeking to gather oral histories. Oral history seeks to use testimony to document, often with an aim of establishing what happened, but also to understand how it happened and what it was like to be involved. Although there is some evidence that there is a therapeutic benefit to be gained in participating in oral history (McCarthy, 2010), the research project did not aim to gather testimony or to provide therapy. Instead, we were interested in what stories of military service were told, what telling these stories did for older veterans and how these stories were used. By considering the role of these stories and their use, we identify how the veteran identity served to affect wellbeing and facilitate social connection, but could also help to exacerbate loneliness and isolate veterans from civilians.

\section{Methods}

This paper uses data from an on-going research project funded by HM Treasury Aged Veterans Fund and administered by the Royal British Legion (RBL). Older veterans (those born before 1 January 1950, aged over 68 at time of writing) were identified by the funder as a group with additional health and well-being needs, and the research aimed to increase understanding of older veterans' lives, selfunderstandings, and distinctive challenges, with a view to informing future interventions and identifying gaps in current supportive services. Our focus was on the role of autobiographical narratives, both telling stories and reading them, as a mode of reasoning and as a tool for maintaining good well-being. In asking participants to explore their life narratives, they also spoke about their post-service lives, being older adults, and the role that their identity as a veteran played in this stage of life.

There was no requirement to engage with veterans' organisations to participate in the research, and one of the aims of the research project was to identify and include those older adults who had not previously been involved with such associations. We recruited participants by advertising on social 
media (mainly Facebook), using posters in public libraries and other relevant community locations, via organisations who worked with older adults (e.g. Age UK) and via organisations who work with veterans (e.g. the RBL). Prospective participants responded to these advertisements and were provided with full information about participating. By keeping our recruitment materials broad and open, calling on former service personnel to participate, we did not presuppose that any person identified as a veteran. We found that many of those who responded to the call to participate did see themselves as veterans and this enabled us to consider the role of the veteran identity and associated community in the lives of older adults.

The project used a semi-structured life-world interviewing approach (Kvale and Brinkmann, 2009) to ask veterans about their experiences of military experiences, framed around questions on themes including comradeship and returning home, to understand how narrating experiences affects wellbeing. Questions were very open and included asking about life before joining military service, and what experiences in service were remembered, with the acknowledgement that these must have been quite varied. Interviews lasted on average 60 minutes, though some were double this length. All interviews were audio-recorded and fully transcribed. Our ethos was to focus on experiences that were predominantly positive or neutral, but as evidence suggests that speaking of negative experiences may also have cathartic impact, we were open to discussion of all experiences as directed by the veterans themselves. As 'civilian' researchers, we expected that the stories that we were able to access from veterans might be shaped by perceived differences in experiences; however, we were interested in listening openly and considering how these perceived differences could be overcome. Although the research team (two medical sociologists and a philosopher) had not worked with military veterans before, one (SC) had conducted significant theoretical work on martial lives, and the other two (LB and BM) had previously worked with diverse excluded groups, predominantly people with severe and enduring mental health difficulties. All the research team had grandparents who had served in the military during WWII, but no further connection with veterans. As a younger, female, 
civilian researcher, the interviewer (BM) was able to use her position to question the older, mostly male participants to provide further details on experiences that they assumed that she could have little or no knowledge of. This helped to surface any tacit assumptions that may have been made if the interviewer had military experience. However, it may also have affected what the veterans chose to disclose. While most seemed open and keen to talk, even about difficult experiences, they may have chosen to avoid discussing certain aspects of service. The interviewer had significant experience of working with people with severe and enduring mental health issues, and so any discussion of trauma was be handled sensitively; veterans were also signposted to appropriate support services in this instance. While our questions often touched on the emotional impact of a situation (e.g. 'how did you feel when you left the forces?'), it was sometimes difficult to capture affective responses, with participants preferring to focus on description or contextualising situations.

Data are drawn here from the first 30 individual interviews conducted with veterans, and also from engagement with 20 veterans across two workshops. Nine participants in this cohort were both interviewed and part of a workshop. All those who volunteered to be interviewed were able to participate; the majority of those who volunteered to attend a workshop also did so if they were available on the date of the workshop. Occasionally volunteers could not attend the first workshop due to other commitments; these volunteers were invited to a later workshop if possible to ensure they were included. These preliminary workshops informed thinking that was translated into a toolkit for working with older adult veterans (Brewster et al., 2019). Lancaster University Research Ethics Committee approved the research, and written informed consent was taken from every participant. We collected demographic data about interview participants but not those who participated in workshops, though they were a similar cohort.

Twenty-seven interview participants were male, and three were female (table 1). The cohort was aged between 68 and 99; over half ( $n=16)$ reported having a disability. Sometimes, due to the 
practical considerations of interviewing frail participants in their own homes, other members of the family (usually a spouse or child) were also present and occasionally contributed to the interview.

\begin{tabular}{llr}
\hline Service & Army & 15 \\
& Aavy & 1 \\
& Territorial Army & 13 \\
& & 1 \\
\hline Length of service & 1-2 years & 11 \\
& 3-10 years & 9 \\
& $21-30$ years & 4 \\
& $30+$ years & 5 \\
\hline
\end{tabular}

\begin{tabular}{llr}
\hline Type of enlistment & WWII Conscription & 1 \\
& National Service & 14 \\
& Voluntary & 15
\end{tabular}

Age range (in 2018, based on year of birth)

$68-70 \quad 5$

$71-79+9$

$\begin{array}{ll}80-89 & 14\end{array}$

$90-100 \quad 2$

$\begin{array}{llr}\text { Gender } & \text { Male } & 27 \\ & \text { Female } & 3\end{array}$

Table 1: Participant characteristics 
The military experiences of those interviewed were very diverse, with participants who had served in the army, navy or air force, including the military police, medical corps, engineering and intelligence services. Participants had enlisted voluntarily, been conscripted or undertaken National Service, and again this shaped their experiences of the services and their length of service, which ranged from two years to 22 years. Service had been conducted in wartime and peacetime, with participants serving in conflicts including WWII, the Korean War, the Falklands conflict, undergoing Cold War nuclear testing on Christmas Island, and being stationed in locations including Palestine, Kenya, Northern Ireland, Germany, Malta, Hong Kong, Singapore and Malaya. Much previous research has focused on specific cohorts of veterans (e.g. WWII veterans or more recent Gulf War veterans) meaning that the data captured from this more diverse cohort with different experiences is especially valuable in identifying perceived connections between veterans.

Analysis was conducted using a data-driven constant comparison approach (Charmaz, 2006) to foreground experience, using themes developed from the data and, where appropriate, concepts from the literature as a sensitising framework (Bowen, 2006). Data were processed using NVivo software and coded using themes drawn from the data. The participant narratives were rich and varied, and by looking across the transcripts, we identified several themes around current experiences of being an older adult and a veteran, which were relevant to review in relation to understanding experiences of older adult well-being.

\section{Results}

Three themes are presented here, which examine the ways in which well-being and social connection was affected by older adults' status as veterans. The first was around their experiences of loneliness, which were not always discussed directly but were implied in conversation. Second, older veterans reported perceptions of fictive kinship, which was often identified as associated with belonging. 
Third, veterans identified the importance of the use of military visual culture in the role of maintaining a point of connection and identifying others with shared experiences.

Although participants had diverse experiences of military services, they often felt that the postmilitary service identity of being a veteran connected them to a community that went beyond association with specific experiences.

Yes, you're a veteran. You're not belonging to a particular service, you're a veteran: you're a veteran of the services. (16: male, 1932, RAF, National Service, 2 years)

This concept of the veteran identity was related to the idea that joining the military was a transformative experience that fundamentally changed a person and continued to affect their identity after leaving the forces. This sharing, or resonating, of experience overcame more widely-accepted barriers to belonging to a community.

I don't know how to describe it, actually, but it was a life-changer, that's all I can say. But I think any entrance into the forces is, because it's a different world, and unless you've actually done it, you can't understand, and you can't explain. But if I met someone and I found out they were ex-forces, immediately there's a bond, even if it's male-female. (09: female, 1949, RAF, Voluntary Enlisted, 3 years)

Once you have been in the service, you're different, because from then on, for ever, you're a former serviceman or ex-serviceman. You can't do anything about that: you are. [...] Because it does change you: it does change you, and once you've been changed, you feel a certain need to associate with other people who've been changed. (18: male, 1933, RAF, National Service, 25 years)

These two participants highlighted key concepts which influence older veteran well-being and show how their experience is different: the exclusion of those who had not served, and the need to 
associate with other veterans, as there was a perceived authentic connection in talking with other exservice personnel.

Many participants had not immediately adopted the identity of a veteran following their service. It was often a number of years before they joined a veterans' organisation or began to accept their military service as part of their identity and talk about it with others.

More so recently, in the last few years, you've been talking about it. When you were younger, you didn't - I mean, I didn't know straight away what you'd done in your life, it's only later on when you started talking about it. (Spouse of 07: male, 1939, RAF, National Service, 5 years)

This later acceptance of the veteran identity was identified as being related to increasing age and a recognition that if these stories were not told now, they would be lost. The later acceptance of a need to connect with other veterans was also seen to relate to the immediate pressures of coming out of service and into civilian life, needing to find employment and establish or re-establish family life. The connections between age, time, and community can be seen clearly in participant narratives.

\section{Loneliness and social isolation}

As stated, few veterans spoke directly about being socially isolated or experiencing loneliness. Instead, references were made to friends who had died, funerals attended, and to the difficulty of talking with other people who had not been part of military services. One participant did raise the issue of loneliness directly, stating that:

The only thing that I think ought to be covered when you do these interviews is what's the state of mind of veterans now? [...] I haven't spoken to anybody for about four days... And people that live on their own, especially veterans, loneliness is a terrible thing, and although I've got friends, they're about eight or nine miles 
away. You might meet them once a week, that's OK, and I never tell my friends that I'm lonely or anything like that. [...] But people like me, and there are a lot of veterans that live on their own, they can be desperately lonely. (14: male, 1939, RAF, National Service, 2 years)

The loneliness associated with older age comes across clearly in this comment, though as will be seen later this participant did use social media to connect with other veterans to lessen this loneliness. Other veterans articulated this loneliness less clearly. For example, a note on an interview transcript reads:

After the recorder turned off he said he had been lonely and speaking to me this morning had lifted his spirits. (17: male, 1938, RAF, National Service, 1.5 years)

As will be explored, the act of talking and sharing stories helps to reduce loneliness and increase social connection. Further traces of loneliness can be seen across participants' interviews as a whole. In one example, a participant wove a thread through the interview, explaining how he had a limited audience to share military experiences with, made good friends but lost them, and expressing a wish for greater connection. The participant started out by confirming the importance of stories told about military service, with a recognition that he found it difficult to share with those outside the veteran community.

You can tell your stories to civilians, or people that have never been in, that's the best way to put it, but they wouldn't understand. (02: male, 1948, Army, Voluntary Enlisted, 27 years)

Later in the interview, the participant did contradict this to an extent, as he highlighted that he felt able to discuss military life with the (younger, female) interviewer, who did not have military experience. 
Well, no, I don't have any problems talking to you about it at all. None whatsoever! You're a listener, you know? (02)

This quote also clearly highlights the impact of feeling like someone is listening to the stories told as being of value. Building on the idea of fictive kinship, participant 02 also identified particular individuals as part of an imagined family, with bonds maintained over time and distance.

The really good friends you do make last a lifetime, you see what I mean? You can not see them for years, and then you'll see them, or you'll go and visit them or they'll come and see you, and it's like you've never been away. (02)

Like many older adults, he was also experiencing loss caused by bereavement. In this case, having met a close friend while serving in the military, it was also the loss of someone who understood and shared experiences that was difficult.

My best mate, my best ever mate, [name], he's just died last year, and I mean, it's like part of me's gone. [...] The experience was there. I miss him a lot. I miss him a lot. (02)

Other participants also talked about the death of close friends in interviews, and how it affected their previously strong ties with particular groups.

We're running short of members now. In fact, one of our closest friends died just about a month ago [...] We're all ageing a little bit, I'm in the mid-80s now. So it's down to, in fact now that he's died, there was about four of us regular over the last two or three years, and because of deaths and, as I say, getting older, it's now down to, there's only really two of us, after happenings in this year alone. (21: male, 1932, RAF, National Service, 2 years) 
The identification of the loss of specific comrades with whom participants served in the forces was a thread that ran through interviews and hinted at the social loneliness experienced by this community. However, there were other connections that could be drawn on within the veteran community that had a positive effect on experiences, including a broader understanding of fictive kinship.

\section{Fictive kinship}

Participants strongly identified the importance of ex-service colleagues in several ways. For some, military service had led to strong friendships that could stand absence over time. Telling stories of military experience was seen as an important aspect of maintaining a bond over time that helped individuals to preserve these close friendships.

I think in all my naval career, I have three friends. [Interviewer: That have lasted?] Yeah. And, you know, we could just meet up with each other as if it was yesterday and not 20 years ago. [Interviewer: When you get together, do you go over stories?] Oh, yes, because that's the key. (12: male, 1943, Navy, Voluntary Enlisted, 31 years)

Others went further to use the metaphor of family to describe the intimacy of the relationship with other veterans.

My closest group of friends for my entire life have been the people I was a boy soldier with, to this day. [...] We share a closer relationship than any other relationships I've ever made in my life. [...] We became family for each other. We lived together 24 hours a day, seven days a week; we had no secrets from each other, none. It's not possible to under these circumstances. (20: male, 1933, Army, Voluntary Enlisted, 16 years) 
The bonds of fictive kinship were seen to be maintained over time and distance; though they served a specific purpose within the context of military service, they did not end when the participant left military service and adopted a veteran identity.

The emphasis is on it's a family, you are part of a family. [...] The bonding is much more than happening to be in a trench with your guys, the bonding is the social side of life. [...] It lasts afterwards: we still feel that. (26: male, 1936, TA, Voluntary Enlisted, 25 years)

These bonds were not just seen to connect individuals who knew each other or had served together. Several participants told a story of being at social events, like weddings, with strangers and sharing a common bond of service.

I was talking to one man, and he said, "You've served." He says, "The way you're talking, you've served." And I just laughed, and says, "Yeah." He said, "We've all got our own way." And it is: we are a community. (12: male, 1943, Navy, Voluntary Enlisted, 31 years)

The importance of this common bond was comforting; the connections of military service meant that one's contributions would not be forgotten, and the veteran community would look after each other in times of need.

I don't know whether you saw the news this morning, did you, about the funeral down in the South? There was this airman who had no family at all, and somebody put online that could anybody attend his funeral, and they had a huge turnout of the RAF and people couldn't get inside the church, even, it was that big. (14: male, 1939, RAF, National Service, 2 years)

The reassurance that even in death the bond of service meant that people would pay their respects and recognise you as a family member reinforces the idea of fictive kinship. 
As mentioned in description of the methods, despite the seeming reluctance amongst our participants to talk in detail about emotional experiences, these bonds of service were openly acknowledged and it was acceptable to talk about the ongoing importance of them.

There was a question that was asked the other day on Facebook, "Do you miss the people you served with?" and there was within 20 minutes, there was 40 replies, "Yes." So, there you are: it says it all. (04: male, 1945, Army, Voluntary Enlisted, 22 years)

The experience of military service was a uniting factor that, for some participants, went beyond individual service experiences. Social networking was identified as a tool that maintained connections over time.

If you've got a problem, you can go on Facebook - any of the sites - and put something on and say, "I've got a question to ask," and you'll get lots and lots of advice. [Interviewer: Would you call it a community?] It's still family. We are a family. And we're not just talking about the army, we're talking about the whole of the armed services. You'll find the navy, air force, royal marines, you know, and everybody's talking on there. (04: male, 1945, Army, Voluntary Enlisted, 22 years)

These stories were seen to resonate across experiences, even when the person had not served in the same location or event. Memories were shared, even though experiences were not. Even for participants who openly acknowledged their loneliness (as highlighted earlier), there was still importance in a shared connection.

[Interviewer]: So sharing stories is an important part of the way in which you maintain that connection? [Participant]: It is, because it helps me to remember, and it helps other people to think of what it was like and I like reading about their 
memories and what they got up to and things. (14: male, 1939, RAF, National

Service, 2 years)

Humour was often used to create a shared bond, as well as to exclude others. Veterans were allowed to tease or banter with each other, and gentle cross-service rivalry was observed in workshops (for example: comments about the luxurious conditions of those in the air force who had access to beds on air bases compared to soldiers sleeping rough in the Bornean jungle). However, like family, this humour could only be used by veterans themselves. Civilians were not welcome to join in the conversation.

"I chat to people on Facebook, we've never met, but we've been in the forces, and they have that thing, this magic thing that you get, so you know you can say - the sense of humour is wicked, you know, there's some things you can say to each other you couldn't say to a civvy, they'd be flabbergasted or offended! But you know, bordering on sexist, racist, all sorts, but meant in a way that's understood by another troop." (09: female, 1949, RAF, Voluntary Enlisted, 3 years)

As researchers, sometimes accepted into the conversation with veterans but also outside of their experiences, we found this humour could be challenging to manage. Veterans were aware that their humour contained content that was considered offensive in civilian life and often couched it with disclaimers that we would not understand or would not find it funny.

\section{Military visual culture}

The HM Armed Forces Veterans' Lapel Badge, a small enamel pin badge launched in 2004, is available for free to anyone who has served in the UK's armed forces. By April 2016, over 84,500 'veterans badges,' as they are commonly known, had been issued to ex-service personnel. The ethos of the veterans badge, which features a composite motif of the army, navy and air force emblems, was to: 
'unite all veterans in recognising the commonality of their service, to encourage a sense of unity and community between surviving veterans and to ignite public recognition of current veterans and their continuing contribution to society.' (Ministry of Defence, 2016)

The veterans badge has a confirmatory power that connects veterans. Informal networks formed by the wearing of the veterans badge were important in connecting older ex-service adults. Participants talked how wearing the veterans badge helped them to identify others who had also served. This was a way of opening a conversation about shared experience that was valued. These conversations helped to maintain ties of fictive kinship and to provide access to what could be described as a mutually beneficial audience-story-teller relationship. Asking someone about their service provided an opportunity to talk about one's own experiences.

It doesn't matter where they served, who they served with, it's there: it's still there. You meet people in the street [...] that little badge really goes a long way, and people say, "Oh, you served," and they'll stop and talk, because their friends or their civilian friends don't understand what they're talking about. (04: male, 1945, Army, Voluntary Enlisted, 22 years)

Wearing the veterans badge also created a form of social support, including practical insights and information sharing.

People that know that you were in the services, if you wear the badge, they can pick you out and see you're a veteran. [...] I always make a point of introducing myself to somebody if they've got a veterans badge on, because there may be something that they need, some question that they want answered. (16: male, 1932, RAF, National Service, 2 years)) 
Participants, who sometimes struggled to express emotions connected with their military service, spoke powerfully about the feelings they had around being able to draw on a visible symbol of their service and how it enabled them to feel part of a community.

Now, I've got the veterans badge for my coat. I walked through [town], and this young lad stopped me and he was selling something [for charity], and I says to him, "You do realise that I'm an OAP, so I haven't got the money to do this," and all he did was look at my badge and he says, "You don't need to," and I got a hug. [...] That is the kind of community we've got. We support each other. It doesn't matter how old you are or where you were, you just do it. And it is that sense of belonging. You belong to something that is huge, and you're a little part of it. (12: male, 1943, Navy, Voluntary Enlisted, 31 years)

This was seen as important to the current experience of being a veteran and had a positive effect on well-being.

This veterans badge, [...] when people see it, it's sort of a nod, as if to say, "We know." So, it's almost like you don't have to say anything. [...] So, you feel like you belong to something. Yes, absolutely. And it's not something you can explain. (09: female, 1949, RAF, Voluntary Enlisted, 3 years)

However, although some participants attended our workshops and engaged with the idea of telling stories about military experience, not all accepted the veteran identity as central to their current lives. Observation notes from workshop two note that in discussions of the veterans badge, one participant reported that he had not even taken his badge out of the box it arrived in. For him, there was no value in adopting this symbol of being a veteran. 


\section{Discussion}

By identifying as a veteran, ex-service personnel were able to access services, events and other people in formal and informal ways, which were seen as positive and beneficial outcomes. The importance of talking about military experience to others with military experience and its effect on well-being can be clearly identified in the data: being a veteran was something that gave life meaning and purpose, in relation to others. Helping other veterans, and knowing that one was part of a community were strong themes which were expressed in positive terms. However, veterans also reported loneliness. By defining themselves as veterans, older adults 'othered' themselves and constructed an identity that was separate from the civilian community. This led to feelings of exclusion and could have increased perceptions of loneliness. Othering was seen amongst a wide diversity of veterans, including ex-service personnel with time-limited military experience (e.g. having done two years of national service rather than being a long-serving veteran) or those who had not left the forces on good terms.

Older adults who had undertaken military service, however long or short, identified a specific need to connect with other veterans. This seemed to help to ease feelings of loneliness by ensuring that they still belonged to that community. However, it also deemed the veteran experience and identity to be exceptional, constructing a barrier between veterans and people who have not served in the military. As ex-service personnel aged, and experienced the increased social isolation and loneliness associated with older age, they faced distinctive challenges which were both exacerbated and mitigated by the adoption of the veteran identity. As was highlighted earlier, the significant decline in the number of veterans noted during the study period show the ongoing challenge of being able to access other veterans.

Stories of military service created an association or bond that could strengthen the idea of similarity and create fictive kin relationships. Often these relationships connected those who had previously 
served together, but as these relationships were lost then other connections with a wider conceptualisation of kin started to supplement them. The veterans badge and social media were used to maintain these new relationships. Similarities can be seen between veterans' use of stories and the literature around illness narratives, which examines the role of stories in the lives of those with chronic illnesses (Bury, 2001).

Returning to Frank's (2010) work, in developing these shared narratives, there was a glossing over of some differences in experience, for a particular purpose or use: to help to form a more coherent community. This is not to say that there was only one story of military life; instead a 'generally disagreed story' (Hunt and Robbins, 2001b) formed and could be used by veterans to say how they were different from those who had not served (civilians).

While veterans found sharing stories of military experience to be valuable, they also felt that there was a limited audience for this sharing. Being alienated from friends and family by experience can be seen in veterans' narratives and those of people with chronic illnesses (Frank, 2017). In this way, for older adult veterans, 'stories turn loneliness into affiliation' (Frank, 2017). Using narratives of military experience to connect, both in the telling of a story and by having an audience who listened to the story, was vital. By adopting the identity of the veteran, older adults were able to find a point of connection that allowed them to access each other as a resource for listening and sharing. As a marginal group, potentially at higher risk of loneliness due to the disruptions in their social relationships caused by military service, accessing other veterans was vital (Perlman and Peplau, 1984). Similar conclusions have been found in explorations of the acceptability of peer support for older adult veterans (Burnell, Needs and Gordon, 2017). Concerns about their own ageing, associated with isolation and loss, motivated them to share these stories while it was still an option to do so. For our participants, adopting the veteran identity provided access to a community that would not have been accessible via other means. Conversely, the reliance on a narrative of shared transformative 
experiences of service life meant that the imagined community was relatively small. In adopting membership of this community, there was also an acknowledgement of a sense of loss, with older veterans seeing themselves as a dying breed and a feeling of exclusion from some aspects of civilian life.

Discussions of 'healthy ageing' have reflected on the need to create specific spaces for groups to interact in. Gendered 'inclusionary social spaces' in which older men perform masculinity (such as the Men's Sheds initiative) have highlighted that not all older adults experience older age or respond to interventions to improve well-being in older age in the same way (Milligan et al., 2015). The findings of our paper further contribute to this discussion by emphasising that for the veteran community, differing understandings of comradeship affect engagement.

Interventions for older adults generally focus on improving skills or social cognition, and providing support or opportunities for interaction (Hawkley and Cacioppo, 2010). A lack of evidence on the effectiveness of such interventions has been identified (Age UK, 2018). Measuring intervention effectiveness is also difficult, relying on self-report or identified proxy factors including number of social contacts.

In the evaluation of such complex interventions, there is an increasing recognition that understanding the context in which the intervention is implemented is vital (Campbell et al., 2000). More recent scholarship has argued for a need to recognise this impact of context on the potential success of health and well-being-related interventions (Bantry-White et al., 2018). For example, working with older adults in an isolated rural community highlighted that the sense of place, tradition and 'sameness' understood by older adults in this setting informed their experience of loneliness and the impact of interventions to reduce isolation (Bantry-White et al., 2018). This 'sameness' can be seen to be key to the findings presented here, showing the benefits of investigating what older adults felt that 
they were able to gain from belonging to this veteran community. Despite diverse experiences in military service, being a veteran provided a semblance of connection that could be used to provide opportunities for social interaction. As well as formal opportunities, managed by veterans organisations, there were also informal opportunities and networks that allowed older adult veterans to find an 'imagined community' (Anderson, 2006) of fictive kin. By providing insight into the community and individuals, we can start to identify the appropriateness of any interventions designed to work with this community.

In focusing on what is important to those interviewed here, we explored the role of access to a shared or imagined community. Current intervention designs most frequently use professional staff to deliver support (Cattan et al., 2005); based on the findings of this study, there may be a role for informal peer or near-peer support. Preliminary work by others supports this claim (Burnell, Needs and Gordon, 2017). Because veterans agree with the idea that only other veterans can understand their experiences, they may find peer support to be more authentic than that experienced in professionally-delivered interventions. Alternatively, other research involving US veterans in oral history projects concluded that: "it is quite possible that simply having the opportunity to tell one's life story to someone who is actively listening would make anyone 'feel better'"' (McCarthy, 2010). Perhaps this is more relevant here than previously considered. The literature on story-telling, well-being and mental health reflects surprisingly little on listening and being heard, though it is recognised in some service evaluations of befriending interventions (Davidson and Rossall, 2015). Again, this forms another avenue for future research.

\section{Strengths and limitations}

One repeated trope encountered in the literature about veterans, and in the data collected here, is that the experience of military service is not fully knowable by those who have not served. In this paper, we do not challenge this idea of inaccessibility, instead accepting our participants' view that 
this unknowability contributes to the disconnection between veterans and civilians. A further common criticism, that veterans were not involved as co-researchers (Bulmer and Jackson, 2016), should also be acknowledged. Future research could empower older adult veterans to represent their own experiences or use participatory action research rather than mediating them via conventional qualitative methods such as interviews (Clough et al., 2006; Bulmer and Jackson, 2016).

The data presented in this paper are drawn from a self-selecting group of older adult volunteers. This means that, while we are confident that they are demographically representative of older adult veterans, we cannot explore how representative they are of wider community views. However, in recruitment we did engage with some veterans who did not find value in accepting the veteran identity or engaging with veterans' organisations. Concerns about veterans' organisations (such as the Royal British Legion) and their lack of inclusivity were raised and informally noted. Future research could work with this group to identify what, if any, impact the rejection of the veteran identity and community had on their mental health and well-being.

There is, perhaps obviously, not just one veteran identity; the intersections of different characteristics mean that those who identify as veterans report diverse experiences and challenges. There is not scope in this paper, for example, to discuss the differences between male and female veterans' experiences, or the experiences of veterans from the LGBT community or those with disabilities. It is important to acknowledge these differences; however, even veterans who told us stories of military experience that one might expect would lead to their rejection of the identity as a veteran (such as sexism or institutional violence) still found a value in accepting the veteran identity.

The focus of this study was broad, therefore there is the possibility that there were opportunities missed in the data collection to explore specific current experiences in more detail. However, much of the literature on well-being acknowledges that it is both difficult to measure, and difficult to get older 
people to reflect on their emotions. A recent systematic review found that there was little research directly addressing this question (Wilson, Hill and Kiernan, 2018). By taking the research interview conversation in a different direction and talking around the subject, this paper contributes a new angle in the discussion, exploring the role that identity plays. It highlights an additional way of thinking about the role of personal context and identity in the design of interventions for older adult wellbeing.

A strength of the research was the reach of the project, which engaged with older adults across the UK, including in isolated rural communities and in major urban areas. By working with a diverse group of veterans, including those who actively used their status as a veteran and considered it central to their identity, we were able to explore the role that this had in community formation.

\section{Conclusion}

This paper does not provide a definitive answer to what a veteran is or could be, but instead reviews how acceptance of veteran identity and narrative affects current circumstances and well-being for older adults. Acceptance of the identity may be premised on the way that the UK government and veterans' organisations have worked to broaden acceptance of what a veteran is. Communication between veterans is now enabled and mediated by social media that allows older adults to find others with shared experiences more effectively. Devices like the veterans badge enable a point of contact in an isolated culture and help older adults to mitigate loneliness by starting conversations around their experiences and finding a source of pride in past experiences. Using the veteran identity as a point of shared connection and belonging to a community was seen to provide something that could not be accessed in other ways and was not accessible to those who had not served in the military. 


\section{References}

Aartsen, M. and Jylhä, M. (2011) 'Onset of loneliness in older adults: Results of a 28 year prospective study', European Journal of Ageing, 8, pp. 31-8. doi: 10.1007/s10433-011-0175-7.

Age UK (2018) Loneliness and isolation - understanding the difference and why it matters. Available at: https://www.ageuk.org.uk/our-impact/policy-research/loneliness-research-and-resources/lonelinessisolation-understanding-the-difference-why-it-matters/ [Accessed 27/01/2020].

Anderson, B. R. O. (2006) Imagined communities : reflections on the origin and spread of nationalism. London: Verso.

Bantry-White, E., O'Sullivan, S., Kenny, L. and O'Connell, C. (2018) 'The symbolic representation of community in social isolation and loneliness among older people: Insights for intervention from a rural Irish case study', Health and Social Care in the Community, 26, pp. e552-9. doi: 10.1111/hsc.12569.

Bowen, G. A. (2006) 'Grounded Theory and Sensitizing Concepts', International Journal of Qualitative Methods, 5, pp. 12-23. doi: 10.1177/160940690600500304.

Brewster, L., Clark, S., McWade, B., Long, E., Giga, S. and Fletcher, I. (2019) 'Military Lives and Transformative Experiences: A toolkit to work with older adult veterans'.

Bulmer, S. and Jackson, D. (2016) "'You do not live in my skin": embodiment, voice, and the veteran', Critical Military Studies. 2, pp. 25-40. doi: 10.1080/23337486.2015.1118799.

Burdett, H., Woodhead, C., Iversen, A. C., Wessely, S., Dandeker, C. and Fear, N. T. (2013) '“Are You a Veteran?" Understanding of the Term "Veteran" among UK Ex-Service Personnel', Armed Forces \& Society. 39, pp. 751-9. doi: 10.1177/0095327X12452033.

Burkitt, I. (1999) Bodies of thought: Embodiment, identity and modernity. Sage.

Burnell, K., Coleman, P. and Hunt, N. (2010) 'Coping with traumatic memories: Second World War veterans' experiences of social support in relation to the narrative coherence of war memories', Ageing and Society. 30, pp. 57-78. doi: DOI: 10.1017/S0144686X0999016X.

Burnell, K., Needs, A. and Gordon, K. (2017) 'Exploring the suitability and acceptability of peer support 
for older veterans', Quality in Ageing and Older Adults, 18, pp. 120-30. doi: 10.1108/QAOA-09-20160036.

Bury, M. (2001) 'Illness narratives: fact or fiction?', Sociology of health \& illness. 23, pp. 263-85. Caddick, N., Phoenix, C. and Smith, B. (2015) 'Collective stories and well-being: Using a dialogical narrative approach to understand peer relationships among combat veterans experiencing posttraumatic stress disorder', Journal of Health Psychology, 20, pp. 286-99. doi: 10.1177/1359105314566612.

Campbell, M., Fitzpatrick, R., Haines, A., Kinmonth, A. L., Sandercock, P., Spiegelhalter, D. and Tyrer, P. (2000) 'Framework for design and evaluation of complex interventions to improve health', BMJ 321, pp. 694-6.

Cattan, M., White, M., Bond, J. and Learmouth, A. (2005) 'Preventing social isolation and loneliness among older people: A systematic review of health promotion interventions', Ageing and Society, 25, pp. 41-67. doi: 10.1017/S0144686X04002594.

Charmaz, K. (2006) Constructing grounded theory: A practical guide through qualitative analysis. London: Sage Publication.

Cieslik, M. (2017) The Happiness riddle and the quest for a good life. Basingstoke: Palgrave Macmillan. Clough, R., Green, B., Hawkes, B., Raymond, G. and Bright, L. (2006) ‘Older people as researchers: Evaluating a participative project', Joseph Rowntree Foundation. Available at: https://www.jrf.org.uk/sites/default/files/jrf/migrated/files/9781859354346.pdf [Accessed: 29/08/2018]

Corley, L. (2017) 'Epistemological Interference and the Trope of the Veteran', Journal of Veterans Studies, 2, pp. 69-78. Available at: https://journals.colostate.edu/jvs/article/view/71.

Cornwell, E. Y. and Waite, L. J. (2009) 'Social Disconnectedness, Percived Isolation, and Health among Older Ad', Jourrnal of Health Sociology Behaviour, 50, pp. 31-48. doi: https://doi.org/10.1177/002214650905000103. Dandeker, C., Wessely, S., Iversen, A. and Ross, J. (2006) 'What's in a Name? Defining and Caring for 
"Veterans": The United Kingdom in International Perspective', Armed Forces \& Society, 32, pp. 16177. doi: $10.1177 / 0095327 \times 05279177$.

Davidson, S. and Rossall, P. (2015) Age UK Evidence Review: Loneliness in Later Life. London. Available at: https://www.ageuk.org.uk/globalassets/age-uk/documents/reports-and-publications/reports-andbriefings/health--wellbeing/rb_june15_lonelines_in_later_life_evidence_review.pdf. [Accessed 27/01/2020].

Davisdon, S. and Rossall, P. (2015) Age UK Evidence Review: Loneliness in Later Life. London.

Dodge, R., Daly, A., Huyton, J. and Sanders, L. (2012) 'The challenge of defining wellbeing', International Journal of Wellbeing, 2, pp. 222-35. doi: 10.5502/ijw.v2i3.4.

Dolan, P., Peasgood, T. and White, M. (2008) 'Do we really know what makes us happy? A review of the economic literature on the factors associated with subjective well-being', Journal of Economic Psychology, 29, pp. 94-122. doi: 10.1016/j.joep.2007.09.001.

Frank, A. W. (2010) Letting Stories Breathe: A socio-narratology. Chicago: Chicago University Press. Frank, A. W. (2017) 'An illness of one's own: Memoir as art form and research as witness', Cogent Arts and Humanities, 4, pp. 1-7. doi: 10.1080/23311983.2017.1343654.

Hansard (2001) War Veterans, HC Deb. Available at: https://hansard.parliament.uk/Commons/200105-08/debates/d9454029-0a83-4c3a-9d36-c7e66aaca4a4/WarVeterans [Accessed 27/01/2020]. Hawkley, L. C. and Cacioppo, J. T. (2010) 'Loneliness matters: A theoretical and empirical review of consequences and mechanisms', Annals of Behavioral Medicine, 40, pp. 218-27. doi: 10.1007/s12160-010-9210-8. HM Government (2018) 'The Strategy for Our Veterans'. Available at: https://www.gov.uk/government/publications/strategy-for-our-veterans [Accessed 27/01/2020]. Hunt, N. and Robbins, I. (2001a) 'The long-term consequences of war: The experience of World War II', Aging and Mental Health, 5, pp. 183-90. doi: 10.1080/13607860120038393. Hunt, N. and Robbins, I. (2001b) 'World War II veterans, social support, and veterans' associations', Aging \& Mental Health. 5, pp. 175-182. doi: 10.1080/13607860120038384. 
Kvale, S. and Brinkmann, S. (2009) InterViews: learning the craft of qualitative research interviewing [2nd edition]. London: Sage.

Lee, H. A., Gabriel, R., Bolton, J. P. G., Bale, A. J. and Jackson, M. (2002) 'Health Status and Clinical Diagnoses of 3000 UK Gulf War Veterans', Journal of the Royal Society of Medicine. 95, pp. 491-97. doi: 10.1177/014107680209501004.

MacManus, D., Dean, K., Jones, M., Rona, R. J., Greenberg, N., Hull, L., Fahy, T., Wessely, S. and Fear, N. T. (2013) 'Violent offending by UK military personnel deployed to Iraq and Afghanistan: a data linkage cohort study', The Lancet, 381, pp. 907-17. doi: https://doi.org/10.1016/S01406736(13)60354-2.

MacManus, D., Fossey, M., Watson, S. E. and Wessely, S. (2015) 'Former Armed Forces personnel in the Criminal Justice System', The Lancet Psychiatry, 2, pp. 121-22. doi:

https://doi.org/10.1016/S2215-0366(14)00095-9.

McAdams, D. P. (1993) The stories we live by: personal myths and the making of the self. New York: The Guilford Press.

McCarthy, E. (2010) "“Is Oral History Good for You?”; Taking Oral History beyond Documentation and into a Clinical Setting: First Steps', Oral History Review, 37, pp. 159-69. doi: 10.1093/ohr/ohq094. Milligan, C., Payne, S., Bingley, A. and Cockshott, Z. (2015) 'Place and wellbeing: shedding light on activity interventions for older men', Aging \& Mental Health, 35, pp. 124-49. doi: 10.1017/S0144686X13000494. Ministry of Defence (2015) 'Annual Population Survey: UK Armed Forces Veterans residing in Great Britain, 2015'. London: HM Government.

Ministry of Defence (2016) The Veterans Lapel Badge, Response to Freedom of Information Act request DBS/SEC/FOI2016.

Ministry of Defence (2019) 'Annual Population Survey: UK Armed Forces Veterans residing in Great Britain, 2017'. London: HM Government.

Nussbaum, M. C. (2005) 'Wellbing, Contracts and Capabilities', in Manderson, L. (ed.) Rethinking 
Wellbeing. Perth: API Network.

Office for National Statistics (2015) 'Measuring National Well-being: Insights into Loneliness, Older People and Well-being, 2015'. London: Office for National Statistics.

Paul, L. A. (2014) Transformative Experience. Oxford University Press. doi:

10.1093/acprof:oso/9780198717959.001.0001.

Perlman, D. and Peplau, L. A. (1984) 'Loneliness research: A survey of empirical findings.', Preventing the harmful consequences of severe and persistent loneliness. Rockville, MD, US: National Institute of Mental Health, pp. 13-46.

Pettigrew, S. and Roberts, M. (2008) 'Addressing loneliness in later life', Aging \& Mental Health. 12, pp. 302-9. doi: 10.1080/13607860802121084.

Rae, H. M (1992) 'Fictive Kin as a Component of the Social Networks of Older People', Research on Aging, 14, pp. 226-47. doi: 10.1177/0164027592142004.

Randall, M. (2017) 'Overview of the UK population: July 2017', Office for National Statistics. London. doi: 10.1007/978-1-60327-281-0_2.

Schechtman, M. (1996) The Constitution of Selves. London: Cornell University Press.

Seligman, M. E. P. (2011) Flourish : a new understanding of happiness and well-being and how to achieve them. London: Nicholas Brealey Publishing.

Steptoe, A., Deaton, A. and Stone, A. A. (2015) 'Psychological wellbeing, health and ageing', Lancet, 385, pp. 640-8. doi: 10.1016/S0140-6736(13)61489-0.

Steptoe, A., Owen, N., Kunz-Ebrecht, S. R. and Brydon, L. (2004) 'Loneliness and neuroendocrine, cardiovascular, and inflammatory stress responses in middle-aged men and women', Psychoneuroendocrinology, 29, pp. 593-611. doi: 10.1016/S0306-4530(03)00086-6. Taylor, C. (1992) Sources of the self : the making of the modern identity. Cambridge: Cambridge University Press.

Taylor, H. O., Taylor, R. J., Nguyen, A. W. and Chatters, L. (2018) 'Social Isolation, Depression, and Psychological Distress Among Older Adults', Journal of Aging and Health, 30, pp. 229-46. doi: 
10.1177/0898264316673511.

Thompson JM, Lockhart W, Roach MB, Atuel H, Bélanger S, Black T, Cox D, Cooper A, de Boer C, Dentry S, Hamner K, Shields D, Truusa, TT (2017) 'Veterans' Identities and Well-being in Transition to Civilian Life - A Resource for Policy Analysts, Program Designers, Service Providers and Researchers', VAC Research Directorate Technical Report. Available at: https://www.veterans.gc.ca/eng/about$\mathrm{vac} /$ research/research-directorate/publications/reports/identities-transition-civil-life [Accessed 27/01/2020]

Veterans Organisation (2019) What is a veteran? The legal definition. Available at:

https://va.org/what-is-a-veteran-the-legal-definition/ [Accessed: 31/07/2019]

Victor, C. R. and Yang, K. (2012) 'The Prevalence of Loneliness Among Adults: A Case Study of the United Kingdom', The Journal of Psychology. 146 pp. 85-104. doi: 10.1080/00223980.2011.613875. Willsey, K. (2015) 'Falling Out of Performance: Pragmatic Breakdown in Veterans' Storytelling', in Diagnosing Folklore. University Press of Mississippi. doi:

10.14325/mississippi/9781496804259.003.0011.

Wilson, G., Hill, M. and Kiernan, M. D. (2018) 'Loneliness and social isolation of military veterans: systematic narrative review', Occupational Medicine, 68 pp. 600-9. doi: 10.1093/occmed/kqy160. Wilson, R. S., Krueger, K. R., Arnold, S. E., Schneider, J. A., Kelly, J. F., Barnes, L. L., Tang, Y. and Bennett, D. A. (2007) 'Loneliness and risk of Alzheimer disease', Archives of General Psychiatry, 64, pp. 234-40. doi: 10.1001/archpsyc.64.2.234.

Woodward, R. and Jenkings, N. K. (2011) 'Military identities in the situated accounts of British military personnel', Sociology, 45, pp. 252-68. doi: 10.1177/0038038510394016. 